\title{
Anxiolytic Effects of the Methanolic Extract of Bacopa monniera in Mice
}

\author{
Md. Abdul Mannan \\ Department of Pharmacy, Stamford University Bangladesh, Dhaka, Bangladesh \\ Email: manna.034@gmail.com
}

How to cite this paper: Mannan, Md.A. (2019) Anxiolytic Effects of the Methanolic Extract of Bacopa monniera in Mice. Pharmacology \& Pharmacy, 10, 298-308. https://doi.org/10.4236/pp.2019.106024

Received: April 13, 2019

Accepted: June 15, 2019

Published: June 18, 2019

Copyright (C 2019 by author(s) and Scientific Research Publishing Inc. This work is licensed under the Creative Commons Attribution International License (CC BY 4.0).

http://creativecommons.org/licenses/by/4.0/

\begin{abstract}
Bacopa monniera Linn. or Brahmi, a plant in the family Scrophulariaceae, is used as a traditional medicine for memory improvement, dementia like anxiety, depression, epilepsy etc. for a long time in Bangladesh. This study evaluated the anxiolytic effects of the methanolic extract of $B$. monniera (MEBM) in animal models of anxiety. For the further tests and phytochemical screening, the whole plant of B. monniera extracted following maceration method. The extract was evaluated for anxiolytic activity using light/dark box, elevated plus maze, marble burying and rota rod tests in mice at the doses of 50, 100 , and $200 \mathrm{mg} / \mathrm{kg}$ body weight. Diazepam $(1.0 \mathrm{mg} / \mathrm{kg})$, an anxiolytic drug used as standard drug. MEBM showed a strong and dose-dependent anxiolytic effects in animal models of anxiety. MEBM significantly increased the time spent in the light compartment, the latency time, and the entries of open arms in light/dark and elevated plus maze tests. In addition, MEBM also significantly decreased the number of buried marbles in marble burying test and increased the time of performance in rota rod test $(p<0.05)$. These were the major findings of this study. Therefore, our results reported that MEBM possesses anxiolytic effects in animal models of anxiety that support the traditional use of this plant as a potent agent to combat anxiety.
\end{abstract}

\section{Keywords}

Bacopa monniera, Scrophulariaceae, Anxiolytic, Animal Model

\section{Introduction}

Anxiety disorders are psychiatric conditions identified as the most common stress-related mood disorders causing disability and hasty death. More than 121 million people are suffering from anxiety in the world according to the World Health Organization (WHO) [1]. For last few years, the priority of 
these disorders in the top chart not only for the high prevalence but also from the burden associated for illness and its treatment [2]. Drugs prescribed for neuropsychiatric disorders have more side effects than they are efficacious. Although benzodiazepines have well-known benefits, their side effects are high up, including muscle relaxation, sedation, physical dependence, memory disturbance, and interaction with other drugs [3]. In these conditions, the efficacy of such drugs is very limited. Therefore, the need for newer, better-tolerated, and more efficacious treatments remains high-rise. Herbal therapies could be considered as alternative or complementary medicines. In the search for novel molecules useful for the treatment of neurological disorders, worldwide medicinal plant research has continued to improvement, demon starting the pharmacological effectiveness of different plant species in a variety of animal models [4].

Bacopa monniera Linn. or Brahmi, a plant in the family Scrophulariaceae, was distributed in the warmer and wet lands regions of the world including Bangladesh. In Bangladesh, this plant is used to relief patients anxiety [5], epilepsy [6], cardiac [7], respiratory [8], digestive disorders, purifies blood and toothache [9], rheumatism and prevent miscarriage [10]. On the other hand, B. monniera shows few gastrointestinal side effects, specifically enlarged bowel movements, nausea, and abdominal cramping [11]. The clinical studies have confirmed the safety of the bacosides in healthy male volunteers [12]. Number of biologically active compounds has been isolated from this plant. They are several chemical groups have been founded such flavonoids [13], alkaloids, glycosides, saponins, and several chemical constituents have been identified such sterols [14], brahmin, nicotine, herpestine, des-saponin glycosides-triterpenoid saponins like Bacoside. The phytochemicals like 3-(a-L-arabinopyranosyl)-O-b-D-glucopyranoside-10 and 20-dihydroxy-16-keto-dammar-24-ene (Bacosides A and B) are the major compounds that exhibit neuropharmacological activities by directly performing on the neurotransmitter's level [13] [15]. The other chemical constituents reported for this plant includes hersaponin [16], betulic acid, monnierin [17], herpestin and brahmine [18], luteolin-7-glucoside, glucoronyl-7-apigenin and gluucoronyl-7luteonin, common phytosteroids [6]. Due to the diverse pharmacological actions of Brahmi, researcher tried to investigate and validate its ethnomedical uses. There are several scientific reports illuminated that bioactive compound of B. monniera would afford for better neuropharmacological outcomes. They found Brahmi as a potent agent with antioxidant [19], antiulcerogenic [20], cognitive enhancer [21], antiinflammatory [22], analgesic, antidiarrhoeal and cytotoxic [23] properties. There is a great interest in the research of B. monniera to explore new therapeutic targets and new molecules acting on the central nervous system. However, the evidence to recommend the use of herbal medicines in the treatment of neurological disorders is still insufficient. Therefore, the main objective of the present study was to evaluate the anxiolytic like-effects of $B$. monniera in different models in mice. 


\section{Materials and Methods}

\subsection{Plant Collection and Extraction}

Fresh plant of B. monniera was collected in June, 2014 from Bogra, Bangladesh. The samples identified by Sarder Nasir Uddin, Senior Scientific Officer, Bangladesh National Herbarium, Dhaka, Bangladesh. A voucher specimen (DACB: 38106) has been deposited in the Herbarium for further reference. About $250 \mathrm{~g}$ of powdered material was soaked in $800 \mathrm{~mL}$ methanol at $25^{\circ} \mathrm{C} \pm 2^{\circ} \mathrm{C}$ for $72 \mathrm{~h}$ in beaker and mixture needs was stirred with a certain interval. Filtrate was filtered 3 times with the help of filter paper and sterilized cotton. The solvent was removed by rotary evaporator (BC-R 201. Shanghai Biochemical Equipment Co. Ltd.) and $10.56 \mathrm{~g}$ extract (Yield 4.22\%) was obtained. This plant extract was used for the phytochemical screening, acute toxicity and anxiolytic activity studies.

\subsection{Animals}

The in vivo experiments were carried out on Swiss albino mice of 3 - 4 weeks age, weighing between $20-25 \mathrm{~g}$. They were procured from the Animal Research Branch of the International Center for Diarrheal Disease and Research, Bangladesh (ICDDR, B). The animals were housed in polyacrylic cages (5 animals/cage) and maintained under standard environmental conditions (temperature: $25^{\circ} \mathrm{C} \pm$ $2^{\circ} \mathrm{C}$, relative humidity: $55 \%-65 \%$ and $12 \mathrm{~h}$ light/ dark cycle). Mice were fed standard laboratory food (Hind Lever diet pellets) and water ad libitum. The animals were acclimatized to the laboratory environment for a period of 14 days prior to performing the experiments. No food has been given to the animals overnight before the experiments. All the experimental mice were treated following the Ethical Principles and Guidelines for Scientific Experiments on Animals (1995) formulated by The Swiss Academy of Medical Sciences and the Swiss Academy of Sciences. The Institutional Ethics Committee of Stamford University Bangladesh approved the entire experimental rules.

\subsection{Drugs and Treatments}

Diazepam for anxiolytic activity assessment $(1 \mathrm{mg} / \mathrm{kg}$; Sedil, Square Pharmaceuticals Ltd.) applied on standard group via oral route. The methanolic extract of $B$. monniera was administered on mice at the doses of 50,100 , and $200 \mathrm{mg} / \mathrm{kg}$ through oral route. Mice were treated with $0.1 \mathrm{ml} /$ mouse for each dose. Control groups were received vehicle $(0.1 \mathrm{ml} /$ mouse $)$ orally. All the tests were performed after $30 \mathrm{~min}$ of administration for better absorption.

\subsection{Phytochemical Screening}

The crude methanolic extract of B. monniera (MEBM) was qualitatively tested for the detection of alkaloids, flavonoids, saponins, tannins, cardiac glycosides, carbohydrates, reducing sugars, proteins, glucosides, terpenoids and steroids [24]. 


\subsection{Acute Toxicity Test}

The mice were arranged into four test groups and a control group $(n=5)$. Deionized water was used for the control group $(0.1 \mathrm{~mL} / \mathrm{mouse})$. The test groups were received 500, 1000, 2000 and $3000 \mathrm{mg} / \mathrm{kg}$ of MEBM respectively through oral route. Immediately after dosing, the animals were under observation for the first $4 \mathrm{~h}$ for any allergic reactions and/or mortality. However, they were further observed for the next $72 \mathrm{~h}$ [25].

\subsection{Light/Dark Exploration Test}

For the test a box $(46 \times 27 \times 30 \mathrm{~cm})$ was used which divided into a small $(18 \times$ $27 \mathrm{~cm})$ and a large $(27 \times 27 \mathrm{~cm})$ compartments. The partition of the compartments has a small hole $(7.5 \times 7.5 \mathrm{~cm})$ for crossing. The small compartment was colored black with a dim red light (60 W; $4 \mathrm{~lx}$ ), on the contrast the large compartment was colored white with a bright illumination (60-W, $400 \mathrm{~lx})$. Mice were treated with vehicle, diazepam and extract. Hence, mice were placed in the middle of the open compartment and observed for $5 \mathrm{~min}$. By observation the data of the time spent in light zone, latency time of the first crossing from one compartment to the other and transition between both compartments were collected directly [26].

\subsection{Elevated plus Maze Test}

The apparatus of the test was an elevated “+” (plus) sign shaped wooden platform. It had four arms (two open arms and two closed arms with $16 \mathrm{~cm}$ high wall) each $25 \mathrm{~cm}$ long and $5 \mathrm{~cm}$ wide. The entire platform was at the height of 50 $\mathrm{cm}$ from the ground. Mice were treated with vehicle, diazepam and extract. After 30 min of absorption, mice were placed in the center of the four arms; was allowed to explore the maze freely. The time spent in open arms and the entry of open arms was counted from the experiment. Each mouse was observed for 10 $\min [27]$.

\subsection{Marble Burying Test}

The mice were placed into a transparent glass box $(30 \times 30 \times 30 \mathrm{~cm})$ which had 25 marbles equally apart from each other on $5 \mathrm{~cm}$ deep sawdust bedding. Five groups contained five mice each were treated with vehicle, diazepam and extract and let them absorb for $30 \mathrm{~min}$. Eventually, each mouse was observed for $30 \mathrm{~min}$. After each observation, mouse was removed from the box and buried (full or two-third) marbles were counted. Sawdust-bedding materials replaced with fresh ones and glass marbles were washed and dried, every time [28].

\subsection{Rota Rod Test}

The Rota rod device was a $3 \mathrm{~cm}$ diameter grip able motorized bar rotating in 20 rpm speed. Mice treated with vehicle, diazepam and extract and placed on the 
rotating rod after $30 \mathrm{~min}$ of absorption. The time spend on the rotating bar was recorded for each mouse with in $3 \mathrm{~min}$. Mice were trained before the test to be able to walk on the bar with ease [29].

\subsection{Statistical Analysis}

The results are presented as mean \pm SEM. The statistical analysis was performed using one way analysis of variance (ANOVA) followed by Dunnett's post hoc test as appropriate using SPSS 11.5 software. Differences between groups were considered significant at a level of $\mathrm{p}<0.05$.

\section{Results}

\subsection{Phytochemical Evaluation}

Preliminary phytochemical screening of the crude extract of $B$. monniera revealed the presence of alkaloids, flavonoids, saponins, tannins, glycosides, terpenoids and steroids.

\subsection{Acute Toxicity}

Acute oral administration of MEBM at the oral doses of $500-3000 \mathrm{mg} / \mathrm{kg}$ did not show mortality or any allergic manifestations during $72 \mathrm{~h}$ inspection except hyperactivity after administration. Therefore, it can be assumed that MEBM possess low toxicity profile and the $\mathrm{LD}_{50}$ is more than $3000 \mathrm{mg} / \mathrm{kg}$.

\subsection{Light/Dark Box Test}

The extract at the doses of 100 and $200 \mathrm{mg} / \mathrm{kg}$ significantly increased the latency time and the time spent in the light compartment. But, the numbers of the light/dark transitions are significantly shown in $200 \mathrm{mg} / \mathrm{kg}(\mathrm{p}<0.05)$. Diazepam $(1 \mathrm{mg} / \mathrm{kg}$,) significantly increased the number of transitions and the time spent in the light compartment while the latency time significantly decreased than 200 $\mathrm{mg} / \mathrm{kg}$ (Table 1).

\subsection{Elevated plus Maze Test}

The extract at doses of 50,100, and $200 \mathrm{mg} / \mathrm{kg}$ significantly increased the time spent in the open arms exploration compared to control group, respectively $(\mathrm{p}<$ 0.05) (Table 2). Consequently, the plant extract increased the number of entries in the open arms of the plus maze test. Moreover, this result was not significant for 50 and $100 \mathrm{mg} / \mathrm{kg}$.

\subsection{Marble-Burying Test}

A significant decrease in the number of marble buried was observed for the extract at doses of 50,100, and $200 \mathrm{mg} / \mathrm{kg}$ when compared to the control group ( $\mathrm{p}$ $<0.05)$. The standard, diazepam also showed significant decrease in the number of marble buried (Table 3 ). 


\subsection{Rota-Rod Test}

In the rota rod test, MEBM treated mice showed significant motor performance with the doses of 100 and $200 \mathrm{mg} / \mathrm{kg}$ compared to control group $(\mathrm{p}<0.05)$. Diazepam also significantly increased the performance time of the mice (Table 4 ).

Table 1. Effects of B. monniera and diazepam on light/dark exploration test.

\begin{tabular}{ccccc}
\hline Treatment & Dose $(\mathrm{mg} / \mathrm{kg})$ & Latency time $(\mathrm{s})$ & Transition number & Time spend in light part (s) \\
\hline Vehicle & - & $16.60 \pm 1.43$ & $9.80 \pm 1.15$ & $73.60 \pm 2.13$ \\
Diazepam & 1 & $30.80 \pm 1.46^{*}$ & $17.00 \pm 1.41^{\star}$ & $166.2 \pm 1.77^{\star}$ \\
MEBM & 50 & $13.80 \pm 1.59$ & $8.80 \pm 1.06$ & $78.0 \pm 2.47$ \\
MEBM & 100 & $24.80 \pm 1.28^{*}$ & $12.60 \pm 1.03$ & $89.00 \pm 1.00^{*}$ \\
MEBM & 200 & $33.20 \pm 1.28^{*}$ & $16.20 \pm 1.46^{*}$ & $127.4 \pm 1.93^{*}$ \\
\hline
\end{tabular}

Values are presented as mean \pm SEM $(n=5) . M E B M=$ Methanolic extract of B. monniera. ${ }^{*} \mathrm{p}<0.05$ compared with the control group (Dunnett's test).

Table 2. Effects of $B$. monniera and diazepam on elevated plus maze test.

\begin{tabular}{cccc}
\hline Treatment & Dose $(\mathrm{mg} / \mathrm{kg})$ & Time spend in open arms $(\mathrm{s})$ & Open arms entry \\
\hline Vehicle & - & $525.00 \pm 1.70$ & $9.60 \pm 1.03$ \\
Diazepam & 1 & $483.40 \pm 1.96^{*}$ & $18.20 \pm 1.56^{*}$ \\
MEBM & 50 & $351.60 \pm 2.16^{*}$ & $9.00 \pm 1.52$ \\
MEBM & 100 & $355.00 \pm 1.41^{*}$ & $13.20 \pm 1.56$ \\
MEBM & 200 & $386.80 \pm 1.28^{*}$ & $17.20 \pm 1.28^{*}$ \\
\hline
\end{tabular}

Values are presented as mean $\pm \operatorname{SEM}(n=5) . M E B M=$ Methanolic extract of $B$. monniera. ${ }^{*} \mathrm{p}<0.05$ compared with the control group (Dunnett's test).

Table 3. Effects of $B$. monniera and diazepam on marble burying test.

\begin{tabular}{ccc}
\hline Treatment & Dose $(\mathrm{mg} / \mathrm{kg})$ & Number of marble burying \\
\hline Vehicle & - & $19.00 \pm 1.00$ \\
Diazepam & 1 & $7.40 \pm 1.12^{\star}$ \\
MEBM & 50 & $15.00 \pm 1.00^{\star}$ \\
MEBM & 100 & $11.80 \pm 1.02^{\star}$ \\
MEBM & 200 & $8.40 \pm 0.51^{\star}$ \\
\hline
\end{tabular}

Values are presented as mean \pm SEM $(n=5)$. MEBM $=$ Methanolic extract of $B$. monniera. ${ }^{*} \mathrm{p}<0.05$ compared with the control group (Dunnett's test).

Table 4. Effects of B. monniera and diazepam on rota rod test.

\begin{tabular}{ccc}
\hline Treatment & Dose $(\mathrm{mg} / \mathrm{kg})$ & Performance time $(\mathrm{s})$ \\
\hline Vehicle & - & $124.80 \pm 1.56$ \\
Diazepam & 1 & $170.80 \pm 1.35^{\star}$ \\
MEBM & 50 & $127.60 \pm 2.01$ \\
MEBM & 100 & $147.80 \pm 1.65^{\star}$ \\
MEBM & 200 & $170.40 \pm 1.72^{\star}$ \\
\hline
\end{tabular}

Values are presented as mean \pm SEM $(n=5)$. MEBM $=$ Methanolic extract of . monniera. $^{*} \mathrm{p}<0.05$ compared with the control group (Dunnett's test). 


\section{Discussions}

In the current study, the anxiolytic effects of the acute administration of MEBM were studied in different animal models of anxiety.

Anxiety disorders are common mental diseases of the central nervous system that include heterogeneous phenomena such as panic disorder, phobias, obsessive-convulsive disorders, and posttraumatic stress disorders [30]. Dysregulation of the GABAergique, serotoninergic, dopaminergic and adrenergic neurosystems have been implicated in the pathophysiology of anxiety [31]. Anxiety can be introduced experimentally in animal with the conflict between the desire to explore novel environment and removal from an illuminated area when they are subjected to light/dark box test [32]. This way, anxiolytic effect can be evaluated throughout the number of transition between the light and dark compartments and time spent in the light area of the box [33] [34]. In our study, MEBM increased the number of transition and the time spent in the light compartment in a dose dependent manner. The higher doses were showed the most anxiolytic-like effects by spending the highest time in the light chamber. This effect was additional evaluated in the elevated plus maze test. The anxiolytic effectiveness of a drug can be verified by a statistically significant increase in rodent activity in the open arms. MEBM increased the time spent in open arms. In this test, higher dose of MEBM was able to show significant anxiolytic effects of entries in the open arms $(p<0.05)$. This anxiolytic effect of MEBM is similar to the diazepam, which induced significant raise in open arm time and in the number of entries into the open arms. The effect of anxiolytic agents is to enhance the reaction to GABA; by opening the $\mathrm{GABA}_{\mathrm{A}}$ activated chloride channels and inhibition of the action potential. This proposed mechanism explains the powerful anxiolytic effect of the extract as it is well known that benzodiazepines have this pharmacological profile.

The marble burying test which is an experimental model, based on the defensive burying behavior elicited in rodents in response to aversive stimuli. The experimental process appears related to obsessive-compulsive disorder, characterized by obsession-recurrent thoughts which lead to accentuated anxiety and discomfort or compulsion-stereotyped behavior or rituals to alleviate the anxiety [35] [36]. Two points support this observation: effective drugs to treat obsessive-compulsive disorder, via the selective inhibitors of serotonin reuptake, diminish the number of marble buried and mice previously exposed to glass marbles continue in intensive burying activity [35]. MEBM was effective in suppressing the marble burying behavior after single treatments. Diazepam was also able to reduce burying behavior. Positive results in these investigational procedures could be due to motor impairment that hinders the execution of behaviors [37]. In order to discard the possibility of false-positive results, the probity of the motor system was evaluated by rota rod test, devised to detect neurological impairment as well as ataxia, sedation or muscle relaxing [29]. Benzodiazepines are the prime drug to treat obsessive compulsive disorder, and it was effective to re- 
duce the number of marble burying after treatments. Due to tolerance to sedative effect and motor impairment, enrichment in rota rod test was predictable after single treatment with diazepam.

The biological effects of the MEBM was observed in this study might be attributed to phytoconstituents in the plant. It has been reported that flavonoids bind with high affinity to the benzodiazepine site of the GABA receptor [38] [39]. Their common bioavailability and particularly their presence in the brain in vivo appear to play an important role in the expression of their effects on the central nervous system (CNS) [40]. Terpenoids and terpenoid related compounds have proven their effectiveness in animal models of anxiety [41]. MEBM was highly effective as an adaptogen, it normalized acute, and chronic stress induced corticosterone changes in animals [42]. MEBM increased the 5-hydroxytryptamine levels in hippocampus, hypothalamus, and cerebral cortex. The higher doses of MEBM produced significantly better anxiolytic effects compared to lorazepam [43].

\section{Conclusion}

Come to a conclusion, the findings of this study have shown that the methanolic extract of $B$. monniera has anxiolytic-like effects in mice. Further neurochemical studies are necessary to elucidate the influence of this extract on the central nervous systems (CNS), which are critically involved in the development of clinical anxiety.

\section{Acknowledgements}

The authors are grateful to Professor Dr. Bidyut Kanti Datta, Chairman, Department of Pharmacy, Stamford University Bangladesh for his permission to use the facilities of the Pharmacology and Phytochemistry Laboratory.

\section{Conflicts of Interest}

The author reports no conflicts of interest. The author alone is responsible for the content and writing of the paper.

\section{References}

[1] Dongen, N.V. and Mason, S. (2012) Impact of Antidepressant Treatment: A Study from the Netherlands. Dove Press Journal: Patients Intelligence, 4, 63-70. https://doi.org/10.2147/PI.S33613

[2] Somers, J.M., Goldner, E.M. Waraich, P. and Hsu, L. (2006) Prevalence and Incidence Studies of Anxiety Disorders: A Systematic Review of the Literature. Canadian Journal of Psychiatry, 51, 100-113. https://doi.org/10.1177/070674370605100206

[3] Barua, C.C., Roy, J.D., Buragohain, B., Barua, A.G., Borah, P. and Lahkar, M. (2009) Anxiolytic Effect of Hydroethanolic Extract of Drymaria cordata L Willd. Indian Journal of Experimental Biology, 47, 969-973.

[4] Galdino, P.M., Nascimento, M.V.M., Sampaio, B.L., Ferreira, R.N., Paula, J.R. and 
Costa, E.A. (2009) Antidepressant-Like Effect of Lafoensi apacari A. St.-Hil. Ethanolic Extract and Fractions in Mice. Journal of Ethnopharmacology, 124, 581-585. https://doi.org/10.1016/j.jep.2009.05.001

[5] Barrett, S.C.H. and Strother, J.L. (1978) Taxonomy and Natural History of Bacopa in California. Systematic Botany, 5, 408-419. https://doi.org/10.2307/2418753

[6] Sen, S., Chakraborty, R., Sridhar, C., Reddy, Y.S.R. and De, B. (2010) Free Radicals, Antioxidants, Diseases and Phytomedicines: Current Status and Future Prospect. International Journal of Pharmaceutical Sciences Review and Research, 3, 91-100.

[7] Valko, M., Leibfritz, D., Moncol, J., Cronin, M.T.D., Mazur, M. and Telser, J. (2007) Free Radicals and Antioxidants in Normal Physiological Functions and Human Disease. The International Journal of Biochemistry and Cell Biology, 39, 44-84. https://doi.org/10.1016/j.biocel.2006.07.001

[8] Mohan, H. (2010) Cell Injury and Cellular Adaptations. In: Textbook of Pathology, Jaypee Brothers Medical Publishers, New Delhi, 21-34. https://doi.org/10.5005/jp/books/11091_3

[9] Kumar, V., Abbas, A.K. and Fausto, N. (2009) Cellular Adaptations, Cell Injury and Cell Death. In: Robbins and Cotran, Eds., Pathologic Basis of Disease, Saunders, Philadelphia, 15-18.

[10] Sudharani, D., Krishna, K.L., Deval, K., Safia, A.K. and Priya (2011) Pharmacological Profile of Bacopa monnieri: A Review. International Journal of Pharmacy, 1, 15-23.

[11] Morgan, A. and Stevens, J. (2010) Does Bacopa monniera Improve Memory Performance in Older Persons? Results of a Randomized, Placebo-Controlled, DoubleBlind Trial. The Journal of Alternative and Complementary Medicine, 16, 753-759. https://doi.org/10.1089/acm.2009.0342

[12] Singh, H.K. and Dharwan, B.N. (1997) Neuropsychopharmacological Effects of the Ayurvedic Nootropic Bacopa monniera Linn. (Brahmi). Indian Journal of Pharmacology, 29, 359-365.

[13] Chaterjee, N., Rastigi, R.P. and Dhar, M.L. (1963) Chemical Examination of Bacopa monniera Wettst. Part I: Isolation of Chemical Constituents. Indian Journal of Chemistry, 1, 212-215.

[14] Bose, K.C. and Bose, N.K. (1931) Observations on the Actions and Uses of Herpestis monniera. Journal of the Indian Medical Association, 1, 60.

[15] Basu, N., Rastogi, R.P. and Dhar, M.L. (1967) Chemical Examination of Bacopa monniera Wettst: Part III Bacoside B. Indian Journal of Chemistry, 5, 84.

[16] Shashtri, M.S., Dhalla, N.S. and Malhotra, C.L. (1959) Chemical Investigation of Herpestis monniera Linn (Brahmi). Indian Journal of Pharmacy, 21, 303.

[17] Basu, U.P. and Dutta, T. (1967) The Structure of Monniera. Tetrahedron Letters, 8, 2937-2941. https://doi.org/10.1016/S0040-4039(00)90891-8

[18] Schulte, K.E., Rucker, G. and El-kersch, M. (1972) Nicotin and 3-Foryl-4-Hydroxy2H-Pyranaus Herpestis monniera. Phytochemistry, 11, 2649-2651. https://doi.org/10.1016/S0031-9422(00)88583-0

[19] Biswas, S.K., Das, J., Chowdhury, A., karmakar, U.K. and Hossain, H. (2012) Evaluation of Antinociceptive and Antioxidant Activities of Whole Plant Extract of $\mathrm{Ba}$ copa monniera. Research Journal of Medicinal Plant, 6, 607-614. https://doi.org/10.3923/rjmp.2012.607.614

[20] Sairam, K., Ch, V.R., Babu, M.D. and Goel, R.K. (2001) Prophylactic and Curative Effects of Bacopa monniera in Gastric Ulcer Models. Phytomedicine, 8, 423-430. 
https://doi.org/10.1078/S0944-7113(04)70060-4

[21] Nathan, P.J., Clarke, J., Lioyd, J., Hutchison, C.W., Downey, L. and Stough, C. (2001) The Acute Effect of an Extract of Bacopa monniera (Brahmi) on Cognitive Functions in Healthy Normal Subjects. Human Psychopharmacology and Clinical Experiment, 16, 345-351. https://doi.org/10.1002/hup.306

[22] Anju (2011) Bacopa monnieri-A Preliminary Study Evaluating Its Anti-Stress Activity in Swiss Albino Mice. Research Journal of Pharmaceutical, Biological and Chemical Sciences, 2, 786-794.

[23] Afjalus, S.M., Chakma, N., Rahman, M., Salahuddin, M. and Kumar, S.S. (2013) Assessment of Analgesic, Antidiarrhoeal and Cytotoxic Activity of Ethanolic Extract of the Whole Plant of Bacopa monnieri Linn. International Research Journal of Pharmacy, 3, 98-101.

[24] Ghani, A. (2003) Medicinal Plants of Bangladesh: Chemical Constituents and Uses. 2nd Edition, Asiatic Society of Bangladesh, Dhaka.

[25] Seth, U.K., Dadkar, N.K. and Kamat, U.G. (1972) Selected Topics in Experimental Pharmacology. Kothari Book Depot, Bombay, 126.

[26] Hascoet, M. and Bourin, M. (1998) A New Approach to the Light/Dark Test Procedure in Mice. Pharmacology, Biochemistry, Behavior, 60, 645-653.

https://doi.org/10.1016/S0091-3057(98)00031-8

[27] Komada, M., Takao, K. and Miyakawa, T. (2008) Elevated plus Maze for Mice. Journal of Visualized Experiments, 22, 1088. https://doi.org/10.3791/1088

[28] Yamada, K., Wada, E. and Yamano, M. (2002) Decreased Marble Burying Behavior in Female Mice Lacking Neuromedin-B Receptor (NMB-R) Implies the Involvement of NMB/NMB-R in 5-HT Neuron Function. Brain Research, 942, 71-80. https://doi.org/10.1016/S0006-8993(02)02696-3

[29] Dunham, N.W. and Miya, T.S. (1957) A Note on a Simple Apparatus for Detecting Neurological Deficit in Mices and Mice. Journal of the American Pharmaceutical Association, 46, 208-209. https://doi.org/10.1002/jps.3030460322

[30] Hyman, S.E. and Rudorfer, M.V. (2000) Anxiety Disorders. In: Dale, D.C. and Federman, D.D., Eds., Scientific American Medicine, Vol. 3, Healtheon/WebMD Corporation, New York, Section 13, Subsection 7.

[31] Kishore, R.N., Anjaneyulu, N., Naga Ganesh, M. and Sravya, N. (2012) Evaluation of Anxiolytic Activity of Ethanolic Extract of Foeniculum vulgare in Mice Model. International Journal of Pharmacy and Pharmaceutical Research, 4, 584.

[32] Crawley, J.N. and Goodwin, F.K. (1980) Preliminary Report of a Simple Animal Behavior for the Anxiolytic Effects of Benzodiazepines. Pharmacology Biochemistry and Behavior, 13, 167-170. https://doi.org/10.1016/0091-3057(80)90067-2

[33] Lepicard, E.M., Joubert, C., Hagneau, I., Perez-Diaz, F. and Chapouthier, G. (2000) Differences in Anxiety-Related Behavior and Response to Diazepam in BALB/cByJ and C57BL/6 Strains of Mice. Pharmacology Biochemistry and Behavior, 67, 739-748. https://doi.org/10.1016/S0091-3057(00)00419-6

[34] Graeff, F.G. and Zangrossi, J.H. (2002) Animal Models of Anxiety Disorders. In: D'Haenen, H., den Boer, J.A. and Willner, P., Eds., Biological Psychiatry, John Wiley \& Sons Ltd., Hoboken, 96-103. https://doi.org/10.1002/0470854871.chxix1

[35] Gyertyan, I. (1995) Analysis of the Marble Burying Response: Marbles Serve to Measure Digging Rather than Evoke Burying. Behavioural Pharmacology, 6, 24-31. https://doi.org/10.1097/00008877-199501000-00005

[36] Ichimaru, Y., Egawa, T. and Sawa, A. (1995) 5-HT1A Receptor Subtype Mediates 
the Effect of Fluvoxamine, a Selective Serotonin Reuptake Inhibitor, on Marble-Burying Behavior in Mice. Japanese Journal of Pharmacology, 68, 65-70. https://doi.org/10.1254/jjp.68.65

[37] Rodgers, R.J., Cao, B.J., Dalvi, A. and Holmes, A. (1997) Animal Models of Anxiety: An Ethological Perspective. Brazilian Journal of Medical and Biological Research, 30, 289-304. https://doi.org/10.1590/S0100-879X1997000300002

[38] Kahnberg, P., Lager, E., Rosenberg, C., Schougaard, J., Camet, L., Sterner, O., Nielsen, E., Nielsen, M. and Liljefors, T. (2002) Refinement and Evaluation of a Pharmacophore Model for Flavone Derivatives Binding to the Benzodiazepine Site of the $\mathrm{GABA}_{\mathrm{A}}$ Receptor. Journal of Medicinal Chemistry, 45, 4188-4201. https://doi.org/10.1021/jm020839k

[39] Wasowski, C., Gavernet, L., IBarrios, I.A., Villalba, M.L., Pastore, V., Samaja. G., Enrique, A., Bruno-Blanch, L.E. and Marder, M. (2012) N, N-Dicyclohexyl Sulfamide and $N, N$-Diphenethyl Sulfamide Are Anticonvulsant Sulfamides with Affinity for the Benzodiazepine Binding Site of the GABAA Receptor and Anxiolytic Activity in Mice. Biochemistry and Pharmacology, 83, 253-259. https://doi.org/10.1016/j.bcp.2011.10.015

[40] Foyet, H.S., Hritcu, L., Ciobica, A., Stefan, M., Kamtchouing, P. and Cojocaru, D. (2011) Methanolic Extract of Hibiscus asper Leaves Improves Spatial Memory Deficits in the 6-Hydroxydopaminelesion Rodent Model of Parkinson's Disease. Journal of Ethnopharmacology, 133, 773-779. https://doi.org/10.1016/j.jep.2010.11.011

[41] Russo, E.B. (2011) Taming THC: Potential Cannabis Synergy and Phytocannabinoid-Terpenoid Entourage Effects. The British Journal of Pharmacology, 163, 13441364. https://doi.org/10.1111/j.1476-5381.2011.01238.x

[42] Sheikh, N., Ahmad, A., Siripurapu, K.B., Kuchibhotla, V.K., Singh S. and Palit, G. (2007) Effect of Bacopa monniera on Stress Induced Changes in Plasma Cortico Sterone and Brain Monoamines in Rats. Journal of Ethnopharmacology, 111, 671676. https://doi.org/10.1016/j.jep.2007.01.025

[43] Bhattacharya, S.K. and Ghoshal, S. (1998) Anxiolytic Activity of a Standardized Extract of Bacopa monniera: An Experimental Study. Phytomedicine, 5, 77-82. https://doi.org/10.1016/S0944-7113(98)80001-9 